BMJ Open

Diabetes

Research

\& Care

\title{
Psychometric validation of the Hypoglycemia Fear Survey-II (HFS-II) in Singapore
}

\author{
Amanda Yun Rui Lam, ${ }^{1}$ Xiaohui Xin, ${ }^{2}$ Wee Boon Tan, ${ }^{2}$ Daphne Su-Lyn Gardner, ${ }^{1}$ \\ Su-Yen Goh ${ }^{1}$
}

To cite: Lam AYR, Xin X, Tan WB, et al. Psychometric validation of the Hypoglycemia Fear SurveyII (HFS-II) in Singapore. BMJ Open Diab Res Care 2017;5:e000329. doi:10.1136/ bmjdrc-2016-000329

Received 19 0ctober 2016 Revised 4 March 2017 Accepted 3 April 2017

\section{CrossMark}

${ }^{1}$ Department of Endocrinology, Singapore General Hospital, Singapore, Singapore

${ }^{2}$ Medicine Academic Clinical Programme, Singapore General Hospital, Singapore, Singapore

Correspondence to Dr Amanda Yun Rui Lam; amanda.lam@mohh.com.sg

\section{ABSTRACT}

Objective We conducted a cross-sectional study to adapt and validate the Hypoglycemia Fear Survey-II (HFS-II) for use in Singapore among persons with type 1 and 2 diabetes mellitus.

Research design and methods A total of 144 patients with type 1 or 2 diabetes on insulin therapy for at least a year completed the HFS-II between September and December 2013 in the Diabetes Center at Singapore General Hospital. We examined the validity (content, concurrent and discriminant validity, and construct validity) and reliability (internal consistency and testretest reliability) of the instrument. Content validity was established using cognitive interviews. Construct validity was assessed using confirmatory factor analysis (CFA) followed by exploratory factor analysis (EFA) after the hypothesized two-factor structure was not confirmed by CFA. Measures of anxiety (Generalized Anxiety Disorder-7 (GAD-7)) and depression (Patient Health Questionnaire-9 (PHQ-9)) were used to establish concurrent validity; history of severe hypoglycemia and status of glycemic control were used to establish discriminant validity. Internal consistency was measured by Cronbach's $\alpha$; test-retest reliability was measured by intracluster correlation coefficient (ICC).

Results Scores of the adapted HFS-II had moderate positive correlations with measures of anxiety and depression scores $\left(r_{\text {anxiety }}=0.41, p<0.01 ; r_{\text {depression }}=0.37\right.$, $p<0.01$. Patients with a recent history of severe hypoglycemia had higher HFS-II scores than those without (mean difference $=9, p<0.01$ ). Patients with poor glycemic control had higher HFS-II scores than those with good control $(p<0.05)$. The original two-factor structure was not confirmed in our sample. EFA results suggested a threefactor solution with the original Behavior subscale splitting into two dimensions. The adapted HFS-II displayed good internal consistency (Cronbach's $\alpha=0.93$ ) and test-retest reliability $(\mathrm{ICC}=0.75)$.

Conclusions The adapted HFS-II has good content, concurrent and discriminant validity, and reliability, but its constructvalidity was not proven with the Behavior subscale turning out to be non-unidimensional.

\section{INTRODUCTION}

Diabetes mellitus is increasingly prevalent in the Asia-Pacific region. In Singapore, the prevalence of diabetes increased from $8.2 \%$ in 2004

\section{Significance of this study \\ What is already known about this subject? \\ - The Hypoglycemia Fear Survey-II (HFS-II) is a valid and reliable measure of hypoglycemia fear in USA and Europe. \\ What are the new findings? \\ $>$ Our study demonstrated that the adapted HFS- II is a valid and reliable instrument to determine hypoglycemia fear among insulin-treated persons with type 1 and type 2 diabetes mellitus in Singapore. \\ How might these results change the focus of research or clinical practice? \\ - The adapted HFS-II may be used as an outcome measure in future studies of interventions to reduce fear of hypoglycemia in Singapore.}

to $11.3 \%$ in $2010 .{ }^{1}$ Intensive glycemic therapy prevents diabetes-related microvascular complications ${ }^{23}$ and cardiovascular disease. ${ }^{45}$ However, attempts to intensify therapy often results in increased frequency of hypoglycemia. ${ }^{6}$

Hypoglycemia is a common adverse event associated with treatment of type 1 and 2 diabetes, especially for patients receiving insulin secretagogues or insulin, or patients with profound endogenous insulin deficiency, such as in type 1 or advanced type 2 diabetes. ${ }^{7}$ Hypoglycemia is a major barrier to achieving optimal glycemic control. ${ }^{8}$ Intensifying treatment often increases hypoglycemic events. ${ }^{9}$ Patients with type 1 diabetes in The Diabetes Complications and Controls Trial and patients with type 2 diabetes in the UK Prospective Diabetes Study (on intensive therapy had significantly increased rates of major hypoglycemic episodes compared with patients on conventional therapy. ${ }^{26}$

Hypoglycemia can occur unpredictably; symptoms range from unpleasant to potentially dangerous. Unsurprisingly, many patients with diabetes significantly fear hypoglycemia. Patients may engage in overcompensatory 
behaviors to avoid hypoglycemia, including reducing insulin dosages or eating excessively. ${ }^{10}$ These behaviors adversely affect metabolic control, increasing risks of diabetes-related complications. Patients with significant hypoglycemia fear have greater psychological distress and a poorer quality of life. ${ }^{11}$ It is important to have a valid and reliable instrument to quantify fear of hypoglycemia, as this may facilitate targeted interventions to reduce this fear.

The original Hypoglycemia Fear Survey (HFS) ${ }^{12}$ was developed in USA in 1987 to assess the levels of fear related to hypoglycemia. The latest revision of the survey, HFS-II, is a valid and reliable measure of fear of hypoglycemia. ${ }^{13-16}$ It consists of two subscales: Behavior (HFS-B) and Worry (HFS-W). The HFS-II has been validated for use in many languages and countries. ${ }^{131516}$ Our study aimed to examine the psychometric properties of HFS-II for adults in Singapore.

\section{RESEARCH DESIGN AND METHODS}

\section{Study population and setting}

Eligible patients included those with type 1 or 2 diabetes on insulin therapy for at least 1 year at the time of the survey, and on active follow-up at the Diabetes Centre at Singapore General Hospital. Patients who were under 21 years of age, unable to communicate in English or Chinese, prisoners or nursing home residents, pregnant, or had cognitive impairment were excluded.

Eligible patients were approached consecutively by a research coordinator during a visit to the Diabetes Centre between September and December 2013. Figure 1 details the recruitment process.

The first 50 patients who completed the HFS-II in English were asked to complete the HFS-II again 2 weeks later, to establish test-retest reliability. Forty-two patients agreed, of which 22 returned the follow-up HFS-II questionnaire by post.

\section{Sample size}

A sample size of 150 was chosen to validate the HFS-II in Singapore. There is no standard formula to calculate the appropriate sample size for validation and refinement of assessment tools, but there are two commonly used rules researchers in this field tend to follow: at least 100 participants or 5-10 participants per variable. There is also evidence that samples of 150 produce accurate solutions if at least 10 variables load at. 40 on each factor. ${ }^{17}$ Given that both factors in the HFS-II had 10 or more variables with a loading of at least 60 in its validation using the US sample ${ }^{13}$ we determined that a sample of 150 was sufficient.

\section{Content validity}

The HFS-II questionnaire was adapted and translated into Mandarin using the nine-step procedure recommended for cross-cultural adaptation of patient-reported outcomes research by Wild et $a l^{18}$ This involves forward translation, backward translation, and harmonization of translated and original questionnaires. To establish content validity, we conducted cognitive interviews using the original English version of HFS-II and its Mandarin

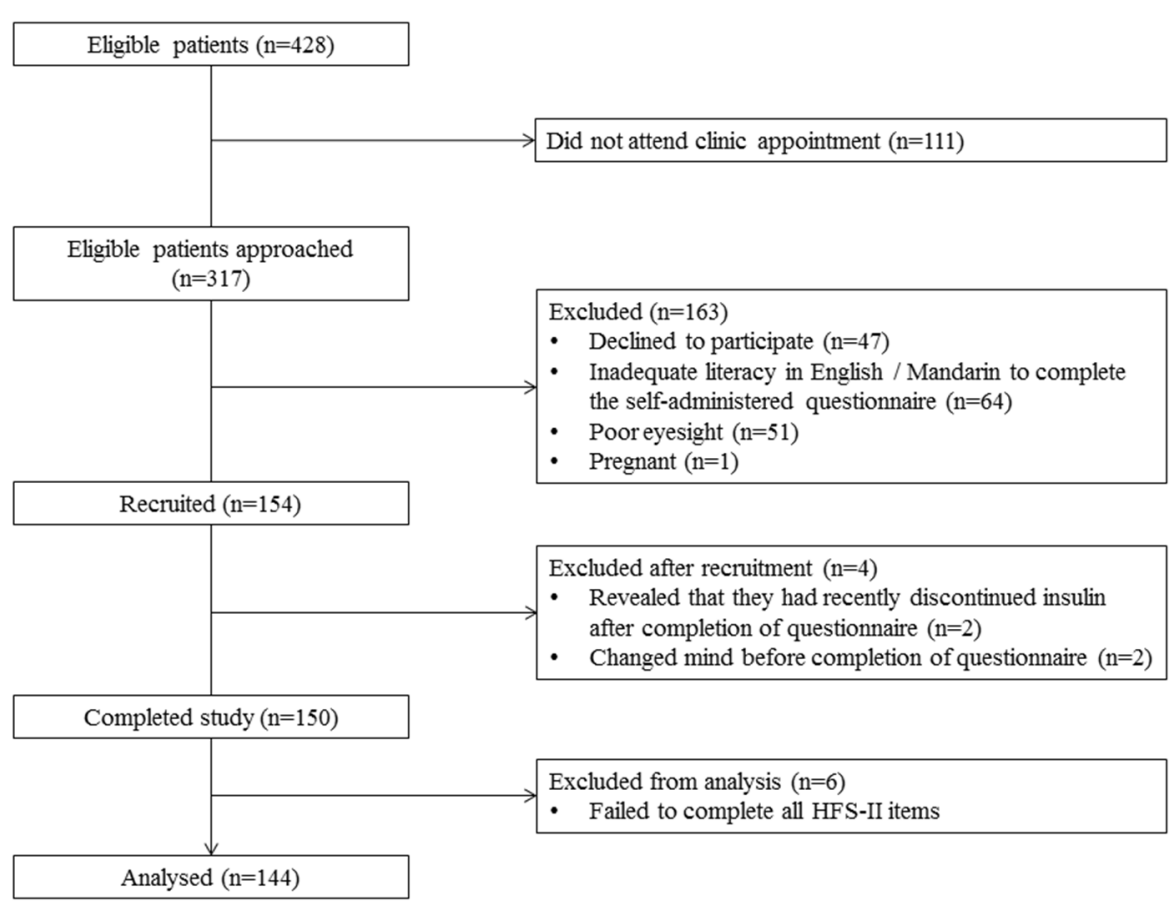

Figure 1 Recruitment and outcomes. 
translation with eligible patients. Appropriate changes were made based on interview results. Input was sought from experts in the field to establish the final version of the questionnaire. To maintain the instrument's integrity, we sought approval from the developers of the instrument for all changes made to the English version.

\section{Concurrent and discriminant validity}

Anxiety and depression were selected to establish concurrent validity. We hypothesized positive correlations between HFS-II, HFS-B, and HFS-W scores and anxiety and depression scores. Recent history of severe hypoglycemia and status of glycemic control were selected to establish discriminant validity. We hypothesized that patients with a history of severe hypoglycemia have higher HFS-II and HFS-W scores than those without. As maladaptive behaviors may undermine blood glucose control, we hypothesized that those with poor glycemic control have higher HFS-II and HFS-B scores. As worries may translate into either adaptive or maladaptive behaviors, the relationship between HFS-W scores and the status of glycemic control is uncertain.

\section{Construct validity}

Construct validity was assessed using confirmatory factor analysis (CFA) to test the fit between the original two-factor structure and our data according to established statistical criteria. Exploratory factor analysis (EFA) was performed after the two-factor structure could not be confirmed by our data.

\section{Measurements}

Fear of hypoglycemia was measured by the HFS-II adapted for use in Singapore. The original HFS-II has 33 items and two subscales: HFS-B (Behavior subscale) and HFS-W (Worry subscale). The 15 items in HFS-B measure behaviors aimed at avoiding hypoglycemia and its possible negative consequences. The 18 items in HFS-W measure various aspects relating to hypoglycemic episodes that provoke anxiety. The items are rated on a five-point Likert scale ranging from 0 (never) to 4 (always). The HFS-II subscale scores and total score are sum scores of all or relevant subset of items ranging $0-60,0-72$, and $0-132$ for the HFS-B, HFS-W, and HFS-II, respectively. Higher scores indicate higher fear of hypoglycemia.

Severity of anxiety was assessed using the Generalized Anxiety Disorder-7 scale (GAD-7) ${ }^{19}$ GAD-7 is a seven-item scale that assesses the presence of anxiety symptoms over the preceding 2 weeks. Responses are rated from 0 (not at all) to 3 (nearly every day). Higher scores indicate more symptoms of anxiety. GAD-7 has good psychometric properties and is used as a screening tool for generalized anxiety disorder in various countries, including Singapore. Severity of depression was assessed using the Patient Health Questionnaire-9 (PHQ-9). ${ }^{20}$ PHQ-9 is a nine-item scale that assesses the presence of each of the nine DSM-IV criteria for depression over the preceding 2 weeks. Responses are rated from 0 (not at all) to 3 (nearly every day). PHQ-9 scores of 5, 10, 15, and 20 represent mild, moderate, moderately severe, and severe depression, respectively. It is used for making criteria-based diagnoses of depressive disorders and is a reliable and valid measure of depression severity used in various countries, including Singapore.

Demographic data were collected from the participants (table 1). Clinical information on the type and duration of diabetes, type and duration of insulin treatment, and most recent haemoglobin A1c (HbAlc) reading assessed using a third-generation immunoturbidimetric assay (Tina-Quant HbA1c Gen.3, Roche) was collected from medical records. Self-reported hypoglycemic events, including severe hypoglycemia in the preceding 12 months, moderate hypoglycemia in the preceding 6 months, and mild hypoglycemia in the preceding 1 month were obtained using the Hypoglycemia History Questionnaire that accompanies the HFS-II instrument.

\section{Ethical considerations}

The study was approved by the SingHealth Centralized Institutional Review Board (Ref no 2013/522/C). Informed consent was obtained from each participant.

\section{Statistical analysis}

Proportion, mean (SD), and median (IQR) were obtained to describe categorical and continuous variables as appropriate.

CFA was performed using Stata V.12.1 to test the construct validity of the HFS-II followed by EFA to explore the factor structure underlying our data after the two-factor structure of the original instrument could not be confirmed by CFA. We used the conventional cutoffs of root mean squared error of approximation (RMSEA) <0.06, Tucker-Lewis Index (TLI) >0.095, Comparative Fit Index (CFI) $>0.95$ and standard root mean square residual (SRMR) $<0.08$ as a good model fit. ${ }^{21}$ We used the eigenvalue $\geq 1$ criterion, supplemented with judgment based on inspection of the scree plot, and the total amount of variance explained to determine the number of factors to retain. We considered an item with a loading $\geq 0.3$ to load onto a factor.

Concurrent validity of HFS-II was assessed by Pearson correlation coefficients of the HFS-II, HFS-B, and HFS-W scores with GAD-7 and PHQ-9 scores. Discriminant validity was assessed using one-way analysis of variance of the HFS-II, HFS-B, and HFS-W scores by the status of glycemic control (HbAlc $\geq 7.5 \%$ or HbAlc $<7.5 \%$ ), and history of hypoglycemic episodes (yes/no).

Internal consistency of the HFS-II as a whole and the HFS-B and HFS-W subscales was assessed using Cronbach's $\alpha$. Values $\geq 0.70$ are deemed satisfactory. Test-retest reliability was assessed using intracluster correlation coefficient (ICC) between the HFS-II, HFS-B, and HFS-W scores obtained at first assessment and those obtained 2 weeks later. 


\begin{tabular}{|c|c|}
\hline & $\begin{array}{l}\mathrm{n}(\%) \text { or } \\
\text { mean (SD) or } \\
\text { median (IQR) }\end{array}$ \\
\hline Age in years & $45.9(14.2)$ \\
\hline \multicolumn{2}{|l|}{ Gender } \\
\hline Female & $72(50.0)$ \\
\hline Male & $72(50.0)$ \\
\hline \multicolumn{2}{|l|}{ Ethnicity } \\
\hline Chinese & $93(65.0)$ \\
\hline Malay & $16(11.1)$ \\
\hline Indian & $28(19.4)$ \\
\hline Other & $7(4.9)$ \\
\hline \multicolumn{2}{|l|}{ Education* } \\
\hline Primary school or lower & $14(9.8)$ \\
\hline $\begin{array}{l}\text { Secondary school or lower secondary } \\
\text { school }\end{array}$ & $34(23.8)$ \\
\hline $\begin{array}{l}\text { Post-secondary (non-tertiary) general or } \\
\text { vocational diploma }\end{array}$ & $28(19.6)$ \\
\hline $\begin{array}{l}\text { Polytechnic diploma, professional } \\
\text { qualifications or other diploma }\end{array}$ & $35(24.5)$ \\
\hline University degree or above & $32(22.4)$ \\
\hline \multicolumn{2}{|l|}{ Type of diabetes } \\
\hline Type 1 & 49 (34.0) \\
\hline Type 2 & $95(66.0)$ \\
\hline Duration of diabetes in years & $14.8(8.7)$ \\
\hline Duration of insulin treatment in years & $9.2(7.8)$ \\
\hline $\begin{array}{l}\text { Most recent } \mathrm{HbA} 1 \mathrm{c} \text { reading before the } \\
\text { survey }(\% /(\mathrm{mmol} / \mathrm{mol}))\end{array}$ & $8.9(1.8) / 74$ \\
\hline \multicolumn{2}{|l|}{ Language of survey } \\
\hline English & $122(84.7)$ \\
\hline Mandarin & $22(15.3)$ \\
\hline \multicolumn{2}{|l|}{ History of hypoglycemic events } \\
\hline $\begin{array}{l}\text { Number of severe hypoglycemic events (in } \\
\text { the } 12 \text { months before the survey) }\end{array}$ & $0(0-1)$ \\
\hline $\begin{array}{l}\text { Number of moderate hypoglycemic events } \\
\text { (in the } 6 \text { months before the survey) }\end{array}$ & $1(0-3)$ \\
\hline $\begin{array}{l}\text { Number of mild hypoglycemic events (in } \\
\text { the } 1 \text { month before the survey) }\end{array}$ & $1(0-2)$ \\
\hline \multicolumn{2}{|l|}{$\begin{array}{l}\text { Proportion of patients experiencing } \\
\text { hypoglycemic events (\%) }\end{array}$} \\
\hline $\begin{array}{l}\text { At least one severe hypoglycemia episode } \\
\text { in the preceding } 12 \text { months }\end{array}$ & 29 \\
\hline $\begin{array}{l}\text { At least one moderate hypoglycemia } \\
\text { episode in the preceding } 6 \text { months }\end{array}$ & 50 \\
\hline $\begin{array}{l}\text { At least one mild hypoglycemia episode in } \\
\text { the preceding } 1 \text { month }\end{array}$ & 57 \\
\hline \multicolumn{2}{|l|}{ Insulin regimen (type 1 diabetes mellitus) } \\
\hline $\begin{array}{l}\text { Premixed insulin ( } \geq 2 \text { injections per } \\
\text { day) } \pm \text { lunchtime quick-acting insulin }\end{array}$ & $1(2.0)$ \\
\hline
\end{tabular}

Continued

\begin{tabular}{lc}
\hline Table 1 Continued & \\
\hline & $\begin{array}{l}\mathbf{n}(\%) \text { or } \\
\text { mean (SD) or } \\
\text { median (IQR) }\end{array}$ \\
\hline $\begin{array}{l}\text { Basal-bolus insulin regimen } \\
\text { Insulin regimen (type 2 diabetes mellitus) }\end{array}$ & $48(98.0)$ \\
$\begin{array}{l}\text { Basal insulin only with oral glucose- } \\
\text { lowering agents }\end{array}$ & $10(10.5)$ \\
$\begin{array}{l}\text { Premixed insulin ( } \geq 2 \text { injections per } \\
\text { day) } \pm \text { lunchtime quick-acting insulin }\end{array}$ & $62(65.3)$ \\
$\begin{array}{l}\text { Basal-bolus insulin regimen } \\
\text { Insulin pump therapy }\end{array}$ & $22(23.2)$ \\
\hline
\end{tabular}

*One respondent did not answer the education level question.

\section{RESULTS}

\section{Sample characteristics}

After excluding six patients who did not complete the HFS-II instrument, the final sample for analysis contained 144 patients (table 1 ).

\section{Mean HFS scores}

The mean (SD) of the HFS-II scores was 24.40 (17.92) and the respective mean (SD) scores for HFS-B and HFS-W were 9.90 (7.95) and 15.12 (13.62). There was no floor or ceiling effect in the full HFS-II or its two subscales. There was a strong Pearson correlation between HFS-B and HFS-W ( $\mathrm{r}=0.515, \mathrm{p}<0.01)$. Both subscales were also strongly correlated with the full HFS-II $\left(\mathrm{r}_{\text {HFS-B \& \&FF-II }}=0.788\right.$, $\left.\mathrm{p}<0.01 ; \mathrm{r}_{\text {HFS-W \& HFS-II }}=0.933, \mathrm{p}<0.01\right)$. The mean (SD) HFS-II, HFS-B, and HFS-W scores were 27.37 (19.05), 10.35 (6.97), and 17.02 (13.62) for patients with type 1 diabetes and 23.24 (18.93), 9.23 (7.89), and 14.01 (13.79) for patients with type 2 diabetes, respectively. Differences in scores were not statistically significant between patients with type 1 and type 2 diabetes.

The proportion of patients experiencing severe hypoglycemia was higher in patients with type 2 diabetes $(34.0 \%$ vs $20.4 \%)$. The proportion of patients experiencing moderate hypoglycemia was higher in patients with type 1 diabetes $(58.3 \%$ vs $46.2 \%)$. These differences were not statistically significant. The proportion of patients experiencing mild hypoglycemia was significantly higher in those with type 1 diabetes $(71.4 \%$ vs $48.9 \%)$.

\section{Content validity}

Changes were made to 17 of the 33 items in the HFS-II instrument based on findings from cognitive interviews to render the instrument more culturally appropriate for patients in Singapore (table 2). All items were modified to end with 'to avoid having low blood sugar' or 'due to concerns about having low blood sugar'. All items in the HFS-W subscale were modified to begin with 'worried about'. These expansions were in response to a key finding from cognitive interviews that patients tended to forget the instructions which provide the context to 
Table 2 Changes made to HFS-II following cognitive interviews

\section{Original HFS-II}

\begin{tabular}{|c|c|c|}
\hline HFS-B1 & Ate large snacks & Ate larger than usual snacks \\
\hline HFS-B2 & Tried to keep my blood sugar above $150 \mathrm{mg} / \mathrm{dL}$ & Tried to keep my blood sugar above $8.3 \mathrm{mmol} / \mathrm{L}$ \\
\hline HFS-B6 & Limited my out of town travel & Limited my overseas travel \\
\hline HFS-B7 & Limited by driving (car, truck, or bicycle) & $\begin{array}{l}\text { Limited my driving (car, truck, bicycle) or operating a } \\
\text { machine }\end{array}$ \\
\hline HFS-B13 & $\begin{array}{l}\text { Kept my blood sugar higher than usual in social } \\
\text { situations }\end{array}$ & $\begin{array}{l}\text { kept my blood sugar higher than usual while interacting } \\
\text { with others }\end{array}$ \\
\hline HFS-B14 & $\begin{array}{l}\text { Kept my blood sugar higher than usual when } \\
\text { doing important tasks }\end{array}$ & $\begin{array}{l}\text { Kept my blood sugar higher than usual when doing } \\
\text { important tasks ('eg, attending a meeting or cooking') }\end{array}$ \\
\hline HFS-B15 & $\begin{array}{l}\text { Had people check on me several times during the } \\
\text { day or night }\end{array}$ & Had people check on me several times a day \\
\hline HFS-W3 & Passing out in public & Fainting in public \\
\hline HFS-W5 & Having a hypoglycemic episode while alone & Having a low blood sugar episode while alone \\
\hline HFS-W7 & Losing control & Losing control of thoughts, emotions or behavior \\
\hline HFS-W8 & $\begin{array}{l}\text { No one being around to help me during a } \\
\text { hypoglycemic episode }\end{array}$ & $\begin{array}{l}\text { No one being around to help me during a low blood sugar } \\
\text { episode }\end{array}$ \\
\hline HFS-W9 & Having a hypoglycemic episode while driving & Having a low blood sugar episode while driving \\
\hline HFS-W11 & Getting a bad evaluation or being criticized & Leaving a bad impression on others \\
\hline HFS-W12 & $\begin{array}{l}\text { Difficulty thinking clearly when responsible for } \\
\text { other }\end{array}$ & $\begin{array}{l}\text { Difficulty thinking clearly when I need to take care of } \\
\text { others }\end{array}$ \\
\hline HFS-W13 & Feeling lightheaded or dizzy & Feeling giddy \\
\hline HFS-W16 & $\begin{array}{l}\text { Low blood sugar interfering with important things } \\
\text { I was doing }\end{array}$ & $\begin{array}{l}\text { Low blood sugar interfering with important things I was } \\
\text { doing ('eg, Attending a meeting or cooking') }\end{array}$ \\
\hline HFS-W17 & Becoming hypoglycemic during sleep & Low blood sugar episode \\
\hline
\end{tabular}

make sense of these items. All changes were approved by the developers of the instrument.

\section{Internal consistency}

The Cronbach's $\alpha$ coefficient for HFS-II was 0.93 with all corrected item-total correlation coefficients $>0.2$ except for two items: HFS-B3 and HFS-B4. The Cronbach's $\alpha$ coefficients for HFS-B and HFS-W were 0.84 and 0.95 , respectively with all corrected item-total correlation coefficients $>0.2$ for HFS-B and $>0.4$ for HFS-W. These suggest that both the full HFS-II and its two subscales have good internal consistency reliability. Test-retest reliability measured by ICC was 0.751 for the total HFS-II $(\mathrm{n}=18)$, and $0.627(\mathrm{n}=18)$ and $0.723(\mathrm{n}=22)$ for HFS-B and HFS-W, respectively, indicating adequate temporal reliability.

\section{Construct validity}

The CFA yielded model fit statistics as RMSEA $=0.094$, $\mathrm{CFI}=0.777$, TLI $=0.762, \mathrm{SRMR}=0.081$, suggesting poor fit between the two-factor structure in the original instrument and our data. Subsequent EFA using principal components extraction method and Varimax rotation method extracted seven factors with eigenvalue $>1$, but the scree plot suggested four likely solutions: one-factor to four-factor solutions. We examined all four solutions starting with one factor only. The forced one-factor model explained $34.74 \%$ of the total variance among the 33 items, but four items HFS-B2, HFS-B3, HFS-B4, and HFS-B 7 had loadings $<0.3$ on the factor.

In the forced two-factor solution, all the $18 \mathrm{HFS}-\mathrm{W}$ items and item HFS-B1 loaded onto the first factor. HFS-B3 did not load on either of the two factors using the criterion of factor loading $<0.3$. Only one item HFS-B11 slightly cross-loaded (factor loading $>0.3$ ) on both factors (factor loading on the first and second factor: 0.303 and 0.706 , respectively). The two factors explained $44.22 \%$ of the total variance, an increase of approximately $10 \%$ from the one-factor solution.

In the forced three-factor and four-factor solutions, all the 18 HFS-W items continued to load onto the first factor, but the 15 HFS-B items started to split into two different factors. In the three-factor solution, all 18 items from the HFS-W subscale formed the first factor, eight items from the Behavior subscale (HFS-B5, HFS-B6, HFS-B8, HFS-B9, HFS-B10, HFS-B11, HFS-B12, and HFS-B15) formed the second factor, and the remaining seven items (HFS-B1, HFS-B2, HFS-B3, HFS-B4, HFS-B7, HFS-B13, and HFS-B14) formed the third factor. While the two factors emerging from the HFS-B subscale have relatively distinct meanings (the second factor comprises self-regulation of diet and treatment regimen and the third factor comprises self-imposed sanctioning of activities), seven 
items from different factors cross-loaded on two factors (factor loadings $>0.3$ ), but there was no item left unclassified with a loading $<0.3$. The three factors accounted for $50.66 \%$ of the total variance, a further $6 \%$ increase from the two-factor solution. In the forced four-factor solution, HFS-B2 was incorporated into the self-imposed sanctioning of activities component, and HFS-B7 formed a fourth factor. These factors are less interpretable than the other three solutions. While the total variance explained further increased to $55.47 \%$, the number of items crossloading on two factors also increased to 8 , and the factors except the Worry subscale are not easily interpretable.

Weighing the increase in the total variance explained and the interpretability of the factors, we concluded that the three-factor solution is the best model to represent the conceptual structure underlying the 33 items in this sample. It is worth noting that the HFS-W subscale was reproduced in the two-factor, three-factor, and four-factor solutions whereas no one single dimension emerged for the items in the HFS-B subscale. Table 3 presents EFA results for the three-factor solution.

\section{Concurrent and discriminant validity}

There was a weak positive correlation between HFS-B scores and the PHQ-9 and GAD-7 scores, and a moderate positive correlation between HFS-II and HFS-W scores and the PHQ-9 and GAD-7 scores (table 4). These were statistically significant. HFS-II and HFS-W scores were significantly higher for those with severe hypoglycemia in the past year than those without $\left(\mathrm{F}(1,142)_{\mathrm{HFS-II}}=7.45\right.$, $\mathrm{p}=0.007) ;\left(\mathrm{F} \quad(1,142)_{\text {Worry }}=7.17, \mathrm{p}=0.008\right)$ with medium effect sizes of 0.49 for HFS-II and 0.47 for HFS-W, respectively. The difference in HFS-B scores between the two groups was not statistically significant (F (1, $142)_{\text {Behavior }}=3.61, \mathrm{p}=0.059$ ) with medium effect size 0.35 . Full HFS-II scores and its subscale scores were significantly higher for patients with HbA1c $\geq 7.5 \%$ compared with patients with HbA1c $<7.5 \% \quad(\mathrm{~F}(1,139)=6.181, \mathrm{p}=0.014$; $\mathrm{F}(1,142)_{\text {Behavior }}=6.142, \mathrm{p}=0.014 ; \mathrm{F} \quad(1,142)_{\text {Worry }}=4.038$, $\mathrm{p}=0.046$ ), with large effect sizes of 0.53 and 0.52 for HFS-II and HFS-B, respectively, and a medium effect size of 0.44 for HFS-W. There was a statistically significant difference in item scores between those with and without severe hypoglycemic episodes and between patients with HbAlc $\geq 7.5 \%$ and those with HbA1c $<7.5 \%$, for the full scale and two subscales.

For patients without severe hypoglycemia in the preceding year and for patients with HbAlc $<7.5 \%$, the median item score for both HFS-II and its two subscales was 0 , with IQR 1 ; for patients with at least one severe hypoglycemic event during the same period, the median item score and the IQR for HFS-B were both 0 , and the median item score for HFS-II and HFS-W was 1, with IQR 2. For patients with HbA1c $\geq 7.5 \%$, the median item score for HFS-II and HFS-B was 0, and that for HFS-W was 1. The IQR for HFS-II and HFS-W was 2, and that for HFS-B was 1.

\section{Reliability}

The Cronbach's $\alpha$ coefficient for HFS-II was 0.93 with all corrected item-total correlation coefficients $>0.2$ except for two items: HFS-B3 and HFS-B4. Cronbach's $\alpha$ coefficients for HFS-B and HFS-W were 0.84 and 0.95 , respectively with all corrected item-total correlation coefficients $>0.2$ for HFS-B and $>0.4$ for HFS-W. This suggests that the full HFS-II and its two subscales have good internal consistency, but the level of internal consistency for HFS-B is lower than HFS-W. Test-retest reliability measured by ICC was 0.751 for the total HFS-II $(n=18)$, and $0.627(\mathrm{n}=18)$ and $0.723(\mathrm{n}=22)$ for HFS-B and HFS-W, respectively, indicating adequate test-retest reliability for the full scale and the two subscales. Test-retest reliability was lower for HFS-B than HFS-W.

\section{CONCLUSIONS}

The purpose of this study was to evaluate the psychometric properties of the Singapore version of HFS-II among patients with type 1 or 2 diabetes who had received insulin therapy for at least 1 year.

The HFS-II instrument demonstrated good content, concurrent, and discriminant validity, but the two-factor structure underlying the original HFS-II could not be confirmed, and therefore its construct validity could not be established based on our sample. But as HFS-W was consistently replicated in the EFA, and the associations between HFS-W and the criterion variables (PHQ-9, GAD-7, history of hypoglycemia, and status of glycemic control) were stronger than the associations between the HFS-B and the criterion variables, we argue that HFS-B has lower validity than HFS-W. This conclusion is similar to findings from other studies. Two dimensions were found underlying HFS-B in a Swedish sample $\mathrm{e}^{15}$ and three dimensions were identified in a Norwegian sample. ${ }^{16}$ The multidimensionality of the HFS-B subscale has been further proven in an international study. ${ }^{14}$

This study also showed that the reliability (internal consistency and test-retest reliability) for HFS-B was lower than for HFS-W. It suggests that HFS-B is less coherent and stable than HFS-W. Therefore, we recommend analyzing the HFS-B and HFS-W subscales separately when measuring fear of hypoglycemia in Singapore until the behavior of HFS-B is more clearly established in future studies. The Singapore version of the HFS-II showed good concurrent and discriminant validity, demonstrated by statistically significant positive correlations with depression and anxiety, significantly different scores for patients with or without a history of severe hypoglycemia and for patients with good or poor control of diabetes.

In our study, HFS-B1 and HFS-B3 were not frequently endorsed items. Singaporeans may not often employ snacking to avoid hypoglycemia, or may not consider portion sizes when they do. Interestingly, reducing insulin dosages in response to hypoglycemia is not a commonly employed strategy in our study population, whereas it was 


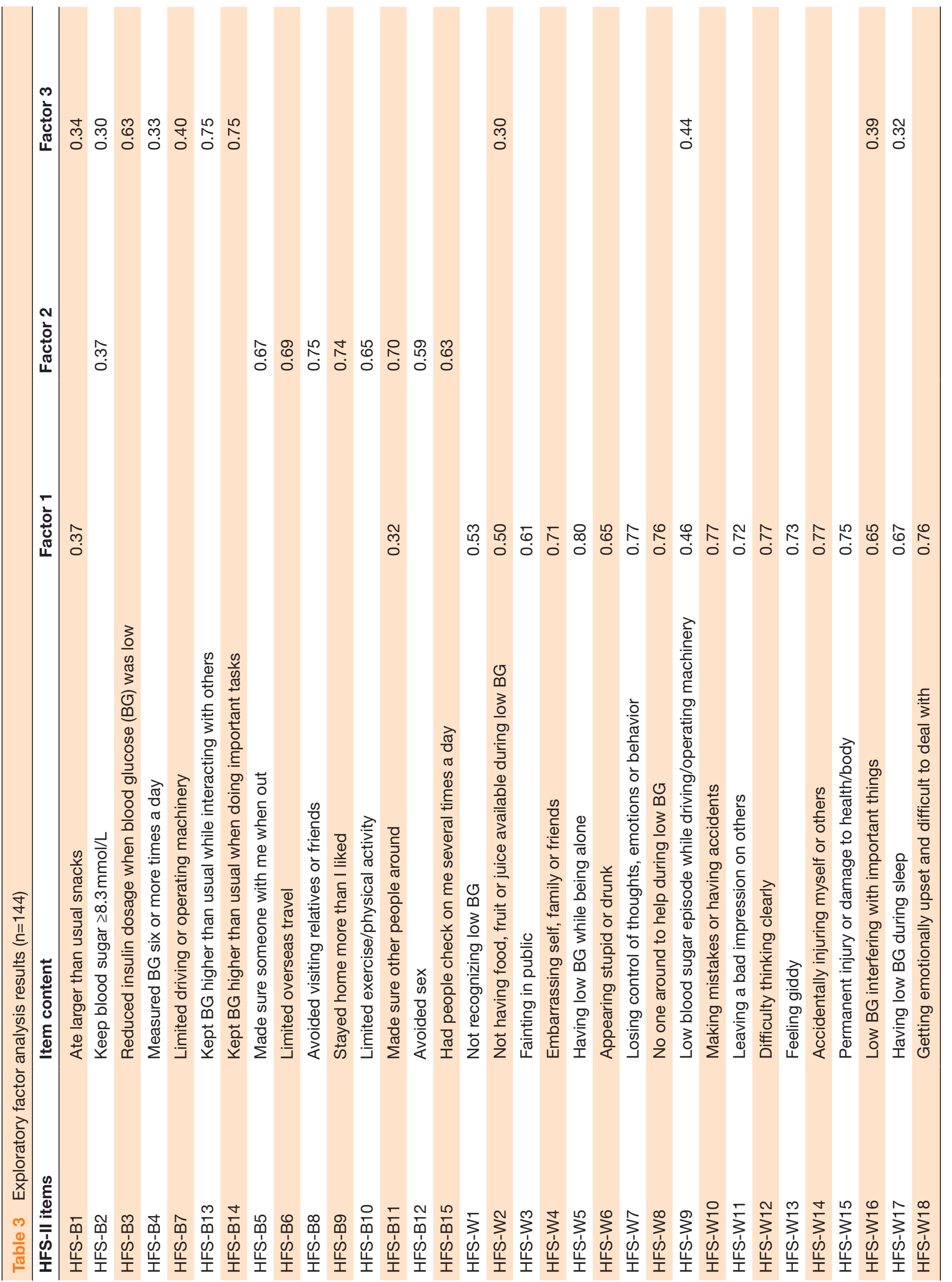




\begin{tabular}{|c|c|c|c|}
\hline & HFS-II & HFS-B & HFS-W \\
\hline $\begin{array}{l}\text { Patient Health Questionnaire-9 items depression } \\
\text { scores }\end{array}$ & $0.367^{\star *}$ & $0.202^{*}$ & $0.395^{\star \star}$ \\
\hline General Anxiety Disorder scores & $0.410^{\star \star}$ & $0.241^{\star \star}$ & $0.432^{\star \star}$ \\
\hline \multicolumn{4}{|l|}{$\begin{array}{l}\text { Had at least one severe hypoglycemia episode in } \\
\text { the past } 12 \text { months prior to the survey }\end{array}$} \\
\hline Scale & $30.35(18.89)^{\star \star}$ & $11.47(7.15)^{*}$ & $18.88(14.18)^{\star \star}$ \\
\hline Item & $0.97(0.61)^{\star \star}$ & $0.83(0.58)^{\star \star}$ & $1.08(0.81)^{\star \star}$ \\
\hline \multicolumn{4}{|l|}{$\begin{array}{l}\text { Had no severe hypoglycemia in the past } 12 \text { months } \\
\text { prior to the survey }\end{array}$} \\
\hline Scale & $21.63(16.90)$ & $8.88(7.59)$ & $12.75(11.81)$ \\
\hline Item & $0.67(0.54)$ & $0.59(0.51)$ & $0.73(0.70)$ \\
\hline \multicolumn{4}{|l|}{ Latest $\mathrm{HbA1c}$} \\
\hline \multicolumn{4}{|l|}{$\geq 7.5 \%(58 \mathrm{mmol} / \mathrm{mol})$} \\
\hline Scale & $26.65(18.02)^{*}$ & $10.5(7.49)^{\star}$ & $16.14(13.18)^{*}$ \\
\hline Item & $0.84(0.59)^{\star}$ & $0.73(0.55)^{\star}$ & $0.92(0.78)^{\star}$ \\
\hline \multicolumn{4}{|l|}{$<7.5 \%(58 \mathrm{mmol} / \mathrm{mol})$} \\
\hline Total & $17.63(16.01)$ & $6.73(7.02)$ & $10.9(10.57)$ \\
\hline Item & $0.55(0.48)$ & $0.46(0.46)$ & $0.63(0.59)$ \\
\hline
\end{tabular}

${ }^{*} p<0.05 ;{ }^{* *} p<0.01$

the most frequently strongly endorsed item in previous studies examining HFS-B. ${ }^{12}$ Reducing insulin dosages may be an appropriate response to recurrent hypoglycemia. This finding may reflect patients' suboptimal understanding of diabetes self-management and a need to intensify patient education. Although HFS-B1 and HFS-B3 were not frequently endorsed in our study, they remain clinically important items and may be further evaluated in subsequent studies.

HFS-II and HFS-W scores were significantly higher for patients experiencing severe hypoglycemia in the past year than those who had not. However, there was no significant difference in the HFS-B scores between these two groups. This may suggest that those experiencing severe hypoglycemia were more worried about hypoglycemic episodes, but did not take steps to prevent future episodes, appropriate or otherwise. Possibilities include inadequate understanding of diabetes self-care, or significant hypoglycemia unawareness in this group, whereby patients lack symptoms of hypoglycemia that trigger compensatory behaviors until mentation is impaired. This parallels the findings of Gold $e t a l$ in which patients with hypoglycemia unawareness worried more about hypoglycemia, but did not modify their behavior accordingly. ${ }^{22}$ HFS-II, HFS-W, and HFS-B scores were higher in patients with poorer glycemic control (HbAlc $\geq 7.5 \%)$, reinforcing that hypoglycemia fear is a barrier to achieving glycemic targets.

\section{Strengths and limitations}

To our knowledge, ours is the first study aiming to adapt and validate the HFS-II in Singapore. A rigorous methodology was employed in the adaptation of the questionnaire for both the English-speaking and Mandarin-speaking Singaporean population.

One potential weakness of this study is the inclusion of patients with type 1 and 2 diabetes. Previously, the HFS-II instrument has been developed and validated mainly among patients with type 1 diabetes. ${ }^{13-16}$ It is based on concerns that patients with type 1 diabetes receiving intensive insulin therapy may have different experiences with hypoglycemia and insulin dose adjustments compared with patients with type 2 diabetes receiving less intensive insulin regimens, such as basal insulin in combination with oral glucose-lowering medications. In our sample, only $10.5 \%$ of patients with type 2 diabetes were on basal insulin only, with the majority on more intensive insulin regimens. The patients with type 2 diabetes in our study likely have comparable experiences with hypoglycemia to patients with type 1 diabetes; thus, we have included them in our analysis.

Our study only included patients who were treated with insulin on follow-up at a specialist diabetes center. They may not be representative of individuals in other clinical settings, for example, patients in the primary healthcare setting or patients receiving only oral glucose-lowering medications. Further studies are also required to validate Malay and Tamil language versions of HFS-II for our multicultural society. Non-response bias may also influence results, as people who declined to participate may have different characteristics.

\section{SUMIMARY}

A valid and reliable instrument to measure the fear of hypoglycemia is essential to identify people with high 
levels of fear. This may allow us to use targeted interventions to address factors leading to hypoglycemic events and maladaptive behaviors preventing good glycemic control. These measures would improve the glycemic control and emotional well-being of people living with diabetes. The Singapore version of the HFS-II overall is a reliable instrument to measure the fear of hypoglycemia, though additional studies are needed to further characterize the HFS-B subscale in Singapore.

Correction notice This paper has been amended since it was published Online First. Owing to a scripting error, some of the publisher names in the references were replaced with 'BMJ Publishing Group'. This only affected the full text version, not the PDF. We have since corrected these errors and the correct publishers have been inserted into the references.

Acknowledgements The authors extend their thanks and appreciation to $\mathrm{Dr}$ Linda Gonder-Frederick and the developers of the original HFS-II for allowing us to use their instrument and for approving our modifications to the version adapted for Singapore. The authors acknowledge the editorial assistance of Yeo Ai Ling, SingHealth Academy, for help with preparing the manuscript.

Contributors AYRL and WBT were involved in the design of the study, acquisition and analysis of data, and drafting of the manuscript. XHX was involved in the design of the study, analysis of data and drafting of the manuscript. DS-L was involved in the analysis of data and drafting of the manuscript. S-YG was involved in the design of the study and drafting of the manuscript.

Funding This research received no specific grant from any funding agency in the public, commercial or not-for-profit sectors.

Competing interests None declared.

Patient consent Detail has been removed from this case description to ensure anonymity. The editors and reviewers have seen the detailed information available and are satisfied that the information backs up the case the authors are making.

Ethics approval SingHealth Centralised Institutional Review Board (CIRB). Provenance and peer review Not commissioned; externally peer reviewed. Data sharing statement Consent for publication of fully anonymised raw data was obtained from study participants. Full datasets are available upon request from the corresponding author.

Open Access This is an Open Access article distributed in accordance with the Creative Commons Attribution Non Commercial (CC BY-NC 4.0) license, which permits others to distribute, remix, adapt, build upon this work non-commercially, and license their derivative works on different terms, provided the original work is properly cited and the use is non-commercial. See: http://creativecommons.org/ licenses/by-nc/4.0/

(C) Article author(s) (or their employer(s) unless otherwise stated in the text of the article) 2017. All rights reserved. No commercial use is permitted unless otherwise expressly granted.

\section{REFERENCES}

1. Singapore : Epidemiology and Disease Control Division. Ministry of Health; 2011. Singapore: National Health Survey, 2010.

2. UK Prospective Diabetes Study (UKPDS) Group. Intensive bloodglucose control with sulphonylureas or insulin compared with conventional treatment and risk of complications in patients with type 2 diabetes (UKPDS 33). Lancet 1998;352:837-53.

3. Nathan DM, Genuth S, Lachin J, et al. The effect of intensive treatment of diabetes on the development and progression of longterm complications in insulin-dependent diabetes mellitus. $N$ Engl $J$ Med 1993;329:977-86.

4. Holman RR, Paul SK, Bethel MA, et al. 10-year follow-up of intensive glucose control in type 2 diabetes. N Engl J Med 2008;359:1577-89.

5. Nathan DM, Cleary PA, Backlund JY, et al. Intensive diabetes treatment and cardiovascular disease in patients with type 1 diabetes. N Engl J Med 2005;353:2643-53.

6. The Diabetes Control and complications Trial Research Group. Hypoglycemia in the diabetes control and complications trial. Diabetes 1997;46:271-86.

7. Seaquist ER, Anderson J, Childs B, et al. Hypoglycemia and diabetes: a report of a workgroup of the American Diabetes Association and the Endocrine Society. Diabetes Care 2013;36:1384-95.

8. Davis S, Alonso MD. Hypoglycemia as a barrier to glycemic control. J Diabetes Complications 2004;18:60-8.

9. Cryer PE. Hypoglycemia: still the limiting factor in the glycemic management of diabetes. Endocr Pract 2008;14:750-6.

10. Wild D, von Maltzahn R, Brohan E, et al. A critical review of the literature on fear of hypoglycemia in diabetes: implications for diabetes management and patient education. Patient Educ Couns 2007;68:10-15.

11. Anderbro T, Gonder-Frederick L, Bolinder J, et al. Fear of hypoglycemia: relationship to hypoglycemic risk and psychological factors. Acta Diabetol 2015;52:581-9.

12. Cox DJ, Irvine A, Gonder-Frederick L, et al. Fear of hypoglycemia: quantification, validation, and utilization. Diabetes Care 1987;10:617-21.

13. Gonder-Frederick LA, Schmidt KM, Vajda KA, et al. Psychometric properties of the hypoglycemia fear survey-ii for adults with type 1 diabetes. Diabetes Care 2011:34:801-6.

14. Gonder-Frederick LA, Vajda KA, Schmidt KM, et al. Examining the behaviour subscale of the hypoglycaemia fear survey: an international study. Diabet Med 2013;30:603-9.

15. Anderbro T, Amsberg S, Wredling R, et al. Psychometric evaluation of the Swedish version of the hypoglycaemia fear survey. Patient Educ Couns 2008;73:127-31.

16. Graue M, Iversen MM, Wentzel-Larsen T, et al. Assessing fear of hypoglycemia among adults with type 1 diabetes - psychometric properties of the Norwegian version of the hypoglycemia fear survey Il questionnaire. Nor Epidemiol 2013;23.

17. Floyd FJ, Widaman KF. Factor analysis in the development and refinement of clinical assessment instruments. Psychol Assess 1995;7:286-99.

18. Wild D, Grove A, Martin M, et al. . Principles of good practice for the translation and cultural adaptation process for PatientReported Outcomes (PRO) Measures: report of the ISPOR task force for translation and cultural adaptation. Value Health 2005;8:94-104.

19. Spitzer RL, Kroenke K, Williams JB, et al. A brief measure for assessing generalized anxiety disorder: the GAD-7. Arch Intern Med 2006;166:1092-7.

20. Kroenke K, Spitzer RL, Williams JB. The PHQ-9: validity of a brie depression severity measure. J Gen Intern Med 2001;16:606-13.

21. Hu Li-tze, Bentler PM. Cutoff criteria for fit indexes in covariance structure analysis: conventional criteria versus new alternatives. Struct Equ Modeling: A Multidisciplinary J 1999;6:1-55.

22. Gold AE, MacLeod KM, Frier BM. Frequency of severe hypoglycemia in patients with type I diabetes with impaired awareness of hypoglycemia. Diabetes Care 1994;17:697-703. 